\title{
Chemical Composition of Lowbush Blueberry Cultivars
}

\author{
Willy Kalt and Jane E. McDonald \\ Agriculture and Agri-Food Canada Research Centre, Kentville, Nova Scotia B4H 1J5, Canada
}

Additional index words. Vaccinium angustifolium, cultivar, maturity, storage, year

\begin{abstract}
The chemical composition of the lowbush blueberry (Vaccinium angustifolium Aiton) cultivars Blomidon, Cumberland, and Fundy were examined at three stages of fruit maturity, before and after refrigerated storage, in a 2-year study. There were differences $(P<0.001)$ related to maturity and cultivar in berry fresh weight, percentage dry matter, fruit firmness, percentage soluble solids, titratable acidity, and the concentration of sugar, acids, and anthocyanins. Among the nine organic and phenolic acids measured, seven acids varied among the maturity groups and eight varied among the cultivars. Between the 2 years of study there was a $60 \%$ difference in total fruit acid content as well as in the relative amounts of each acid. The 2-year mean profile of lowbush blueberry acids was distinctly different from that

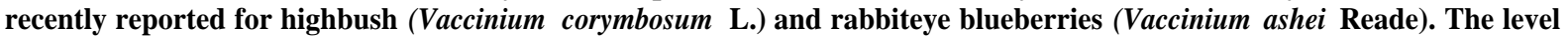
of certain acids as well as the concentration of anthocyanins increased during cold storage. Estimation of sugar concentration by percentage soluble solids overestimated sugar concentration by 3070 . Acid measurement by titration underestimated acid content as measured by HPLC by $61 \%$. Results of this study illustrate the variation in the chemical composition of lowbush blueberry fruit among cultivars, maturities, and seasons, and can be used to compare lowbush blueberries with other Vaccinium species.
\end{abstract}

Lowbush blueberries (Vaccinium angustifolium) are native to Eastern Canada and the Northeast United States, where wild stands are commercially managed and harvested. Lowbush fruit is small compared to highbush (Vaccinium corymbosum) or rabbiteye blueberries (Vaccinium ashei). Since stands of lowbush blueberries are made up of numerous wild clones, the commercial lowbush product is more heterogeneous than commercial highbush or rabbiteye blueberries. The mineral and vitamin content of lowbush blueberries was reported by Bushway et al. (1983) and the total N, amino acid, anthocyanin, flavanol, and sugar content was examined by Goueli(1976). Lowbush blueberries contain equal amounts of glucose and fructose but do not contain sucrose (Barker et al., 1963, Goueli, 1976) while highbush blueberries contain fructose, glucose, and small amounts of sucrose (Eck, 1988). Ehlenfeldt et al. (1994) recently reported the organic acid composition of highbush and rabbiteye blueberries and suggest that these two Vaccinium species are distinguishable based on their acid profiles.

The purpose of this study was to examine the chemical profile of lowbush blueberry cultivars with emphasis on fruit components that influence sensory quality. The study examines fruit at three stages of maturity, before and after storage, and during two harvest seasons.

\section{Materials and Methods}

Lowbush blueberries of clones 'Blomidon', 'Fundy', and 'Cumberland' were collected in 2 consecutive years from plots that fruited in alternate years, located about $0.3 \mathrm{~km}$ apart at the Agriculture and Agri-Food Canada Experimental Farm in Sheffield Mills, Nova Scotia. Fruit of each cultivar was harvested with a rake from the top of each of three shrubs. For each cultivar, three maturity stages were sorted based on size and color differences. Blue fruit with red coloration at the stem end were classified as

Received for publication 5 May 1995. Accepted for publication 21 Sept. 1995. We gratefully acknowledge the advice of K.B McRae and S.E. Fillmore in experimental planning and statistical analysis and L.C. Hamilton for technical assistance. The cost of publishing this paper was defrayed in part by the payment of page charges. Under postal regulations, this paper therefore must be hereby marked advertisement solely to indicate this fact. underripe. Berries that were entirely blue were size-graded through a $10-\mathrm{mm}$ screen. The large berries that were retained in the screen were classified as overripe, while fully blue berries that passed through the screen were classified as ripe. Samples ( $\geq 80 \mathrm{~g}$ ) from each of the nine cultivar-maturity combinations were divided in half. One half of the sample was analyzed immediately. The other half was analyzed after 2 weeks of storage at $1 \mathrm{C}$ in fiberboard pint containers under a vented polyethylene overlay.

Berry firmness was measured on two 20-g aliquots of berries by measuring the force $(\mathrm{N})$ required to move a piston through a 30$\mathrm{mm}$ distance of a plastic Ametek cell (36 mm in diameter) (Ametek, Hunter Spring Division, Hatfield, Pa.) containing a 20g berry sample. The two aliquots of compressed berries were immediately blended in a Virtis homogenizer (The Virtis Co., Gardner, New York) for 2 min. An aliquot of the fruit homogenate was taken for measurement of refractive index, titratable acids and anthocyanins. Refractive index of the homogenate was measured using a hand-held, temperature-compensated refractometer (Atago, Japan). Titratable acidity was measured in a weighed aliquot of homogenate (about $1 \mathrm{~g}$ ) using $0.01 \mathrm{~N} \mathrm{NaOH}$ and a semi-automated titrator (Multi-Dosimat E-415; Metrohm AG, Switzerland), using phenolphthalein as an endpoint indicator. Anthocyanin content was measured by the $\mathrm{pH}$ differential method of Wrolstad (1976) using the extinction coefficient of malvidin-3-glucoside $(28,000)$. The remainder of the homogenized sample was immediately stored at $-70 \mathrm{C}$ before samples were prepared for HPLC analysis of sugars, organic acids and phenolic acids.

Samples for HPLC analysis of sugars, and organic and phenolic acids were prepared by blending $20 \mathrm{~g}$ of the frozen berry homogenate with $40 \mathrm{ml}$ of distilled water using a Virtis homogenizer. The mixture was vacuum filtered through Whatman \#42 filter paper. For sugar and organic acid analysis $4 \mathrm{ml}$ of filtrate was passed through a Sep-Pak $\mathrm{C}_{18}$ cartridge (Waters Scientific, Mississauga, Canada) that had been rinsed with $2 \mathrm{ml}$ of $100 \%$ acetonitrile and 5 $\mathrm{ml}$ of water. The last two $\mathrm{ml}$ of juice effluent were collected and filtered through a Millex-HV, 0.45- $\mu \mathrm{m}$ filter (Millipore, Mississauga, Canada). HPLC analysis was carried out using a Beckman System Gold HPLC (Beckman Instruments, San Ramon, Calif.).

Sugars in a $20-\mu l$ sample were separated by isocratic elution 
with $75 \%$ acetonitrile $/ 25 \%$ water $\left(2.5 \mathrm{ml} \cdot \mathrm{min}^{-1}\right)$ on a Brownlee Sphen 5 -Amino column $(4.6 \times 220 \mathrm{~mm}, 5 \mu \mathrm{m}$ particle size $)$, and were detected by their refractive index. Organic acids in a $20-\mu \mathrm{l}$ sample were separated on a Waters Radial-Pak NovaPak $\mathrm{C}_{18}$ column $(8 \times 100 \mathrm{~mm})$ by isocratic elution with $50 \mathrm{~mm}$ potassium phosphate, $\mathrm{pH} 2.4$, at a flow rate of $2.5 \mathrm{ml} \cdot \mathrm{min}^{-1}$. Organic acids were detected at $214 \mathrm{~nm}$ with a Beckman 167 scanning UV detector. Sugars and organic acids were identified by comparison with retention times of pure standards.

For phenolic acid analysis a 10-ml aliquot of juice filtrate was passed through a 10 -cc column containing $1 \mathrm{ml}$ of Polyamide (Riedel-de Haën AG, Germany). The column was rinsed with $3 \mathrm{ml}$ of water and phenolic acids were eluted in $40 \mathrm{ml}$ of methanol by discarding the first 1 to $2 \mathrm{ml}$, and collecting the remaining $40 \mathrm{ml}$ of eluant. Robinin ( $1 \mathrm{mg}$ ) was added as an internal standard and the methanol mixture was evaporated to dryness in a flash evaporator at $45 \mathrm{C}$. The dried sample was redissolved in $1 \mathrm{ml}$ of methanol and filtered through a Millex-HV, 0.45- $\mu \mathrm{m}$ filter. Phenolic acids in a $20-\mu l$ sample were separated on a Beckman Ultrasphere XL OCTYL $(4.6 \times 150 \mathrm{~mm}, 5-\mu \mathrm{m}$ particle size $)$ column using the following gradient of tetrahydrofuran (THF) and $0.1 \%$ trifluoroacetic acid (TFA), at $1.5 \mathrm{ml} \cdot \mathrm{min}^{-1}: 20 \%$ THF: $80 \%$ TFA (0-1 rein): gradient to 40\% THF: $60 \%$ TFA (1-15 rein); 40\% THF: $60 \%$ TFA (15-17 rein); gradient to $75 \%$ THF: $25 \%$ TFA (17-18 min); $75 \%$ THF: $25 \%$ TFA (18-19 rein); gradient to $20 \%$ THF: 80\% TFA (19-21 rein); 20\% THF: 80\% TFA (21-27 rein). Peaks were detected at $270 \mathrm{~nm}$ and identified by comparison with retention times of pure standards.

Analysis of variance procedures of Genstat 5 (Payne et al., 1993) were used to analyze all results. Unless otherwise indicated, only differences of $P<0.001$ are presented. Anthocyanin data, expressed as $\mathrm{mg} \cdot \mathrm{g}^{-1}$ dry weight (DW) (as malvidin 3-glucoside), were transformed to $\log _{10}$ to equalize experimental variances among factorial combinations. For the same reason, titratable acidity, and acid concentration, expressed as equivalents/g DW plus 1 were transformed to $\log _{10}$. A Spearman procedure, which ranks two variates based on their correlations coefficients (Payne et al., 1993), was used to compare percentage soluble solids (SS), with sugars measured by HPLC and TA with total HPLC acids. Bivariate regression was used to relate sugar content to percentage SS, and HPLC acid content to titratable acidity.

\section{Results and Discussion}

Maturity related differences were observed in berry fresh weight (FW), percentage DM, berry firmness, percentage SS, and sugar, acid, and anthocyanin concentration (Table 1). FW and percentage DM were about $63 \%$ and $16 \%$ greater respectively, in overripe compared to underripe berries. Berry firmness was $37 \%$ lower in the ripest compared to the least ripe fruit. The percentage SS and glucose and fructose concentration (measured by HPLC) were about $40 \%$ and $56 \%$ higher, respectively, in overripe compared to the underripe berries (Table 1). No sucrose was detected in the samples, confirming earlier reports by Goueli (1976) and Barker et al. (1963). Titratable acidity was about 54\% lower in the most mature, compared to least mature berries, while the total acid measured by HPLC was about $28 \%$ lower (Table 1). Monomeric anthocyanins, which accounted for greater than $85 \%$ of the total anthocyanin content in the samples (data not shown), were substantially higher in the ripe fruit than in underripe fruit and slightly higher compared to overripe berries (Table 1). Although the exact maturity of the fruit was unknown, maturity-related differences in percentage DM, firmness, percentage SS, TA, and acid, sugar, and anthocyanin concentration substantiated the assignment of berries into three ripeness classes based on surface color and size. This suggests that surface color and size are suitable criteria to assess lowbush blueberry fruit maturity. Surface color has been shown to be a good indicator of percentage SS and TA among highbush cultivars $\left(r^{2}=0.7-0.9\right)$ (Dekazos and Birth, 1970); however, this correlation is not as strong within clones of wild lowbush $(r=0.44$ 0.51) (Kalt et al. 1995). Fruit size is somewhat more closely related to ripeness ( $r=0.53-0.60)$ than surface color (Kalt et al., 1995). Although fruit size and ripeness appeared to be correlated, other factors not related to maturity can affect blueberry fruit size, such as seed number, water status and crop load.

There were cultivar-related differences in berry FW, percent-

Table 1. Physical and chemical characteristics of lowbush blueberry cultivars at three stages of maturity.

\begin{tabular}{|c|c|c|c|c|c|c|c|c|c|}
\hline Maturity & Cultivar & $\begin{array}{l}\text { Berry fresh wt } \\
\text { (g/berry) }\end{array}$ & $\begin{array}{c}\text { Dry } \\
\text { matter } \\
(\%)\end{array}$ & $\begin{array}{l}\text { Firmness } \\
(\mathrm{N})\end{array}$ & $\begin{array}{c}\text { Soluble } \\
\text { solids } \\
(\%)\end{array}$ & $\begin{array}{c}\text { Glucose }+ \\
\text { fructose } \mathrm{e}^{\text {zy }} \\
(\%)\end{array}$ & $\begin{array}{c}\text { Titratable } \\
\text { acidity }^{x} \\
\text { (meq/g dry wt) }\end{array}$ & $\begin{array}{c}\text { Total } \\
\text { acid } \\
\text { (meq/g dry wt) }\end{array}$ & $\begin{array}{l}\text { Anthocyanins } \\
\left(\mathrm{mg} \cdot \mathrm{g}^{-1} \text { dry wt) }\right.\end{array}$ \\
\hline \multirow[t]{4}{*}{ Unripe } & Blomidon & 0.217 & 13.80 & 97.52 & 7.52 & 3.69 & 0.730 & 1.96 & 4.38 \\
\hline & Cumberland & 0.220 & 14.62 & 72.28 & 8.71 & 5.42 & 0.928 & 2.00 & 6.77 \\
\hline & Fundy & 0.305 & 12.63 & 95.68 & 7.70 & 4.29 & 1.227 & 2.22 & 7.08 \\
\hline & Mean & 0.247 & 13.68 & 88.49 & 7.98 & 4.47 & 0.961 & 2.06 & 6.08 \\
\hline \multirow[t]{4}{*}{ Ripe } & Blomidon & 0.292 & 15.95 & 79.17 & 10.72 & 7.40 & 0.466 & 1.59 & 9.51 \\
\hline & Cumberland & 0.344 & 16.23 & 49.00 & 12.18 & 8.73 & 0.461 & 1.43 & 10.14 \\
\hline & Fundy & 0.357 & 14.03 & 72.76 & 10.55 & 7.04 & 0.845 & 1.90 & 13.46 \\
\hline & Mean & 0.331 & 15.40 & 66.98 & 11.15 & 7.72 & 0.591 & 1.64 & 11.04 \\
\hline \multirow[t]{4}{*}{ Overripe } & Blomidon & 0.631 & 16.81 & 58.45 & 13.13 & 11.04 & 0.354 & 1.40 & 8.88 \\
\hline & Cumberland & 0.600 & 17.32 & 49.94 & 14.22 & 10.87 & 0.332 & 1.36 & 8.91 \\
\hline & Fundy & 0.761 & 14.89 & 58.74 & 11.92 & 9.15 & 0.652 & 1.68 & 12.86 \\
\hline & Mean & 0.664 & 16.34 & 55.71 & 13.09 & 10.35 & 0.446 & 1.48 & 10.22 \\
\hline \multicolumn{2}{|c|}{ Grand mean } & 0.414 & 15.14 & 70.39 & 10.74 & 7.51 & 0.666 & 1.73 & 9.11 \\
\hline \multicolumn{2}{|c|}{ SE } & 0.0127 & 0.359 & 3.730 & 0.2860 & 0.439 & 0.0160 & 0.034 & 0.591 \\
\hline \multicolumn{2}{|l|}{$P<0.001$} & $\mathrm{C}^{\mathrm{w}}, \mathrm{M}, \mathrm{C} \times \mathrm{M}$ & $\mathrm{C}, \mathrm{M}$ & $\mathrm{C}, \mathrm{M}$ & $\mathrm{C}, \mathrm{M}$ & $\mathrm{C}, \mathrm{M}$ & $\mathrm{C}, \mathrm{M}$ & $\mathrm{C}, \mathrm{M}$ & $\mathrm{C}, \mathrm{M}, \mathrm{C} \times \mathrm{M}$ \\
\hline
\end{tabular}

${ }^{\mathrm{g} / 100 \mathrm{~g} \text { fresh weight. }}$

${ }^{x}$ Back-transformed from log data.

${ }^{y}$ Measured by HPLC.

${ }^{\mathrm{w}} \mathrm{C}=$ cultivar, $\mathrm{M}=$ maturity. 
Table 2. Organic and phenolic acids of lowbush blueberry cultivars of different maturities.

\begin{tabular}{|c|c|c|c|c|c|c|c|c|c|c|c|}
\hline Maturity & Cultivar & Chlorogenic & Citric & Malic & Quinic & Acetic & Caffeic & p-Coumaric & Ferulic & Shikimic & Total \\
\hline \multicolumn{12}{|c|}{$\%$} \\
\hline \multirow[t]{4}{*}{ Unripe } & Blomidon & 14.97 & 33.04 & 28.37 & 20.34 & 2.64 & 0.24 & 0.26 & 0.00 & 0.15 & \\
\hline & Cumberland & 6.95 & 38.59 & 30.69 & 21.12 & 1.71 & 0.38 & 0.17 & 0.22 & 0.17 & \\
\hline & Fundy & 8.61 & 36.73 & 27.53 & 24.10 & 2.28 & 0.37 & 0.23 & 0.00 & 0.15 & \\
\hline & Mean & 10.18 & 36.12 & 28.86 & 21.85 & 2.21 & 0.33 & 0.22 & 0.07 & 0.16 & \\
\hline \multirow[t]{4}{*}{ Ripe } & Blomidon & 13.36 & 33.32 & 30.52 & 19.05 & 2.81 & 0.51 & 0.28 & 0.00 & 0.15 & \\
\hline & Cumberland & 9.35 & 36.30 & 32.95 & 18.36 & 1.80 & 0.66 & 0.18 & 0.23 & 0.16 & \\
\hline & Fundy & 10.07 & 35.30 & 30.12 & 21.42 & 1.90 & 0.82 & 0.19 & 0.00 & 0.17 & \\
\hline & Mean & 10.93 & 34.97 & 31.20 & 19.61 & 2.17 & 0.66 & 0.22 & 0.08 & 0.16 & \\
\hline \multirow[t]{4}{*}{ Overripe } & Blomidon & 10.49 & 37.73 & 32.86 & 16.23 & 1.86 & 0.50 & 0.19 & 0.00 & 0.15 & \\
\hline & Cumberland & 8.41 & 36.96 & 34.61 & 17.55 & 1.32 & 0.68 & 0.13 & 0.17 & 0.17 & \\
\hline & Fundy & 11.53 & 35.71 & 30.64 & 19.27 & 1.47 & 1.07 & 0.15 & 0.00 & 0.16 & \\
\hline & Mean & 10.14 & 36.80 & 32.70 & 17.68 & 1.55 & 0.75 & 0.16 & 0.06 & 0.16 & \\
\hline \multicolumn{2}{|c|}{ Grand mean } & 10.42 & 35.96 & 30.92 & 19.72 & 1.98 & 0.58 & 0.20 & 0.07 & 0.16 & \\
\hline \multicolumn{12}{|c|}{$\mu e q / g d r y w t$} \\
\hline \multirow[t]{4}{*}{ Unripe } & Blomidon & 293.7 & 648.3 & 556.8 & 399.2 & 51.71 & 4.65 & 5.17 & 0.00 & 2.86 & 1962.4 \\
\hline & Cumberland & 138.5 & 768.7 & 611.3 & 420.6 & 34.03 & 7.48 & 3.40 & 4.41 & 3.39 & 1991.8 \\
\hline & Fundy & 187.4 & 799.0 & 598.9 & 524.2 & 49.49 & 8.10 & 4.95 & 0.00 & 3.28 & 2175.3 \\
\hline & Mean & 206.5 & 738.7 & 589.0 & 448.0 & 45.08 & 6.75 & 4.51 & 1.47 & 3.17 & 2043.2 \\
\hline \multirow[t]{4}{*}{ Ripe } & Blomidon & 212.9 & 531.0 & 486.5 & 303.7 & 44.81 & 8.07 & 4.48 & 0.00 & 2.37 & 1593.8 \\
\hline & Cumberland & 134.2 & 521.1 & 473.0 & 263.6 & 25.81 & 9.52 & 2.58 & 3.35 & 2.33 & 1435.5 \\
\hline & Fundy & 191.2 & 670.2 & 571.8 & 406.7 & 36.09 & 15.58 & 3.61 & 0.05 & 3.15 & 1898.4 \\
\hline & Mean & 179.4 & 574.1 & 510.4 & 324.7 & 35.57 & 11.06 & 3.56 & 1.13 & 2.62 & 1642.6 \\
\hline \multirow[t]{4}{*}{ Overripe } & Blomidon & 156.6 & 563.3 & 490.6 & 242.3 & 27.84 & 7.49 & 2.78 & 0.00 & 2.22 & 1493.1 \\
\hline & Cumberland & 115.9 & 509.1 & 476.8 & 241.8 & 18.18 & 9.31 & 1.82 & 2.34 & 2.33 & 1377.6 \\
\hline & Fundy & 194.7 & 602.9 & 517.3 & 325.4 & 24.78 & 18.12 & 2.48 & 0.00 & 2.63 & 1688.3 \\
\hline & Mean & 155.7 & 558.4 & 494.9 & 269.8 & 23.60 & 11.64 & 2.36 & 0.78 & 2.39 & 1519.7 \\
\hline \multicolumn{2}{|c|}{ Grand mean } & 180.6 & 623.7 & 531.4 & 347.5 & 34.75 & 9.81 & 3.48 & 1.13 & 2.73 & 1735.1 \\
\hline \multicolumn{2}{|l|}{ S E } & 22.89 & 21.65 & 20.94 & 19.74 & 5.35 & 1.40 & 0.781 & 0.246 & 0.140 & \\
\hline \multicolumn{2}{|l|}{$P<0.001$} & $\mathrm{C}$ & $\mathrm{C}, \mathrm{M}$ & & $\mathrm{C}, \mathrm{M}$ & $\mathrm{C}$ & $\mathrm{C}, \mathrm{M}$ & $\mathrm{C}$ & $\mathrm{C}, \mathrm{C} \times \mathrm{M}$ & $\mathrm{C}, \mathrm{C} \times \mathrm{M}$ & \\
\hline
\end{tabular}

age DM, berry firmness, TA, percentage SS, and sugar and anthocyanin concentration (Table 1). 'Fundy' had the highest FW and the lowest percentage DM, compared to the other two cultivars. 'Cumberland' berries were less firm than the other two cultivars. 'Cumberland' also had the highest percentage SS at all stages of ripeness and its sugar content was greater than 'Blomidon' and 'Fundy' in the underripe and ripe berries. 'Fundy' berries had the highest TA and total acid compared to the other two cultivars and also the highest concentration of anthocyanins. Goa and Mazza ( 1994) also noted that 'Fundy' berries had a higher anthocyanin concentration than 'Blomidon' and 'Cumberland'.

Although there was a highly significant correlation $(P<0.001)$ between percentage SS and sugar content, the discrepancy in their actual values was as high as $44 \%$. The Spearman procedure, which was used to match a given sample percentage SS with the sample with the most closely correlated sugar concentration, matched percentage SS and sugar in the same sample in 5 of the 18 cultivarmaturity combinations. Regression analysis of percentage SS and sugar content indicated that, over all ripeness categories, the nonsugar contribution to the percentage SS measurement was $4.3 \%$ (i.e., 0 intercept on percentage SS axis). Part of the nonsugar contribution to percentage SS would be due to dissolved acids in the sample. There was a highly significant $(P<0.001)$ correlation between TA and total acid although the total acid equivalents, as measured by HPLC, were up to $70 \%$ greater than equivalents measured by TA. In the Spearman procedure, total HPLC acids and TA were matched in the same sample in 2 of the 18 cultivarmaturity combinations. Fresh berry homogenate was used to measure titratable acidity and percentage SS, while previously frozen berry homogenate was used for sugar and acid analysis on HPLC. Freezing and thawing samples may have ruptured cell walls and membranes releasing acids that were not accessible for titration in the fresh sample. However, a fresh homogenate (i.e., a suspension) may yield a higher level of titratable acid than would a juice sample if acids were associated with particulate matter in the sample. Although phosphoric acid was not observed, this acid, as well as phenolic acids, may not be completely neutralized at the titration endpoint for phenolphthalein (Ulrich, 1970). The overestimate of sugar content by percentage SS and underestimate of acid content with titratometric measurements would be exaggerated when these values are expressed as a ratio, i.e., percentage SS/TA.

The 2-year mean contribution of citric, malic, quinic, and chlorogenic acid were $36 \%, 31 \%, 20 \%$, and $10 \%$, respectively, among the cultivar and ripeness combinations (Table 2). The minor acids, acetic, caffeic, p-coumaric, ferulic and shikimic acid were present in a ratio of about $66: 20: 6: 3: 5$, and their contribution to the total acid equivalents was $3.0 \%$. The profile of major acids in lowbush fruit was distinctive from the profiles of organic acids recently documented for highbush and rabbiteye blueberries (Ehlenfeldt et al., 1994). Succinic acid, which is $17 \%$ and $50 \%$ of the organic acid in highbush and rabbiteye blueberries, respectively (Ehlenfeldt et al., 1994) was not observed in the lowbush blueberries. In highbush blueberries the mean percentage contribution by citric acid is about $75 \%$, succinic acid is $17 \%$, while malic and quinic acid are present at $<5 \%$ each. In another study of highbush blueberry acids (Markakis et al., 1963), chlorogenic 
Table 3. Differences in the concentration of acids, measured by HPLC and titration in 2 harvest years.

\begin{tabular}{lcccc}
\hline & \multicolumn{2}{c}{ Year 1} & \multicolumn{2}{c}{ Year 2 } \\
\cline { 2 - 5 } Acid & $\mu \mathrm{eq} / \mathrm{gDW}$ & $\%$ & $\mu \mathrm{eq} / \mathrm{gDW}$ & $\%$ \\
\hline Chlorogenic & 181.8 & 17.33 & 176.0 & 6.76 \\
Citric & 290.5 & 27.70 & 1016 & 39.01 \\
Malic & 137.3 & 13.09 & 1056 & 40.54 \\
Quinic & 350.2 & 33.39 & 339.5 & 13.03 \\
Acetic & 70.78 & & 0 & \\
Caffeic & 12.18 & & 7.48 & \\
p-Coumaric & 3.81 & $8.50^{z}$ & 4.33 & $0.66^{z}$ \\
Ferulic & 0.87 & & 1.40 & \\
Shikimic & 1.48 & & 3.97 & \\
Total & 1048 & 100.01 & 2605 & 100.00 \\
Titratable acidity & 469.4 & & 805.5 & \\
\hline
\end{tabular}

${ }^{\mathrm{x}}$ Total \% of acetic, caffeic, p-coumaric, ferulic, and shikimic acids.

Table 4. Effect of 2 weeks of refrigerated storage on lowbush blueberry composition.

\begin{tabular}{lccc}
\hline \hline Variate & Week 0 & Week 2 & $P<0.05$ \\
\hline Pressure (N) & 68.96 & 70.28 & $\mathrm{C} \times \mathrm{S}^{z}$ \\
Titratable acidity $^{\mathrm{y}}$ & 42.59 & 39.83 & $\mathrm{~S}$ \\
Anthocyanins $^{\mathrm{x}}$ & 7.67 & 9.15 & $\mathrm{~S}$ \\
Acetic acid $^{\mathrm{N}}$ & 2.00 & 2.17 & $\mathrm{~S}$ \\
Citric acid & 36.72 & 41.95 & $\mathrm{~S}$ \\
Malic acid & 32.95 & 38.29 & $\mathrm{~S}$ \\
Quinic acid & 62.74 & 69.70 & $\mathrm{~S}$ \\
Shikimic acid & 0.441 & 0.509 & $\mathrm{~S}$ \\
\hline
\end{tabular}

${ }^{\bar{z}} \mathrm{~S}=$ storage.

${ }^{y}$ As mg citric acid/g dry weight

${ }^{\mathrm{x}}$ As $\mathrm{mg} \cdot \mathrm{g}^{-1}$ dry weight.

acid, a phenolic acid, contributed about $16 \%$ to the total acid concentration. In rabbiteye fruit, the percentage contribution by citric, succinic, malic and quinic acid was about 10\%, 50\%, 34\%, and $6 \%$ respectively. The suggestion that Vaccinium species are chemically distinguishable has been supported by results of this study where lowbush blueberries had an acid profile different from those reported for highbush and rabbiteye blueberries by Ehlenfeldt et al. (1994). Highbush, rabbiteye and lowbush blueberries may have distinctive sensory properties since fruit acids differ in their taste characteristics. For example succinic acid is intensely bitter, while malic acid alone or in combination with citric acid is sour. Compared to succinic, malic and citric acids, the sensory properties of quinic acid are weak (Rubico and McDaniel, 1992).

Not all of the major acids had a lower concentration in the more ripe lowbush fruit (Table 2). While citric and quinic acid were 24\% and $40 \%$ lower in overripe compared to underripe berries, respectively, the concentration of malic acid, which contributed $31 \%$ to the total acid concentration, was present at similar levels among all maturity groups. Also, chlorogenic acid did not vary consistently with fruit maturity. Kushman and Ballinger (1968) found in highbush blueberries that citric acid was $30 \%$ to $40 \%$ lower in overripe compared to underripe fruit, while there were no maturity-related changes in other acids.

There were significant cultivar differences in citric, quinic, chlorogenic, but not malic acid (Table 2). All five of the minor acids were present in the three cultivars in significantly different $(P$ $<0.001)$ concentrations. Markakis et al. (1963) reported similar levels of organic and phenolic acids in the highbush cultivars Jersey and Rubel. Ehlenfeldt et al. (1994) reported a similar organic acid profile among highbush cultivars, with the exception of 'Bluetta', which is $1 / 4 \mathrm{~V}$. angustifolium. Highbush cultivars that were $1 / 16 V$. angustifolium had organic acid profiles that were indistinguishable from pure $V$. corymbosum. The lowbush cultivars examined in this study were $100 \%$ Vaccinium angustifolium therefore cultivar differences in their acid profile reflect chemical heterogeneity within the species.

Fruit acid concentration was different between the 2 years of the study, with the quantity of acids, as measured by HPLC, $60 \%$ higher in the second year (Table 3 ). The higher acid content in the second year was due primarily to a 6.7-fold increase in malic acid and a 2.5-fold increase in citric acid. Quinic and chlorogenic acid were at about the same concentration in the two harvest seasons. Acetic acid was absent during the season when acid content was high, but contributed almost $7 \%$ to the total acid equivalents when acid content was low. The percentage acid profile of the major acids (i.e., chlorogenic, citric, malic and quinic) was substantially different between the two years (Table 3 ). These year-to-year differences in the acid composition indicate that lowbush blueberry fruit composition must be examined for more than one season to establish a characteristic acid profile. Year-to-year differences in acid content have been also noted for raspberries (Riaz and Bushway, 1994).

There was a $30 \%$. difference in the level of anthocyanins between the 2 years of the study (data not shown). Differences in anthocyanin concentration have been noted in grapes, where yearto-year differences within a cultivar were greater than differences among cultivars (Cacho et al., 1992). In the present study the magnitude of differences in the anthocyanin concentration were about the same between cultivars of the same maturity, as within a cultivar between years.

After 2 weeks of refrigerated storage there was a decline in titratable acidity of about $7 \%$ although there were increases in five of the nine acids (Table 4). Anthocyanins increased by $18 \%$ during refrigerated storage. Berry firmness increased slightly during storage; 'Blomidon' and 'Cumberland' fruit were less firm, while 'Fundy' were more firm.

In summary, extensive maturity and genotypic differences have been demonstrated in the chemical composition of lowbush blueberry fruit. The distinctive acid profile of lowbush blueberries supports the notion that acid profiles of blueberry fruit may be useful in distinguishing Vaccinium species (Ehlenfeldt et al., 1994). However year-to-year differences in the content of various acids must be considered when determining a characteristic acid profile for Vaccinium species. This study represents the most comprehensive examination to date of the chemical components important to the sensory quality of lowbush blueberry fruit.

\section{Literature Cited}

Barker, W.G., F.A. Wood, and W.B. Collins. 1963. Sugar levels in fruits of lowbush blueberries at four physiological ages. Nature 198:810-811. Bushway, R.J., D.F. McGann, W.P. Cook, and A.A. Bushway. 1983. Mineral and vitamin content of lowbush blueberries (Vaccinium angustifolium Ait.) J. Food Sci. 48(6):1878-1880.

Cache, J, P. Fernandez, V. Ferreira, and J.E. Castells. 1992. Evolution of five anthocyanidin 3-glucosides in the skin of the Tempranillo, Monstel and Garnacha grape varieties and the influence of climatological variables. Amer. J. Enol. Viticult. 43(3):244-248.

Dekazos, E.D. and G.S. Birth. 1970. A maturity index for blueberries using light transmittance. J. Amer. Soc Hort. Sci. 92:292-295.

Eck, P. 1988. Fruit development, p. 66-90. In: Blueberry science. Rutgers Univ. Press Rutgers, N.J. 
Ehlenfeldt, M.K., F.I. Meredith, and J.P. Ballington. 1994. Unique organic acid profile of rabbiteye vs. highbush blueberries. HortScience 29:321-323.

Goa L. and G. Mazza. 1994. Quantitation and distribution of simple and acylated anthocyanins and other phenolics in blueberries. J. Food Sci. 59(5):1057-1059.

Goueli, S.A. 1976. Biochemical and physiological studies of the developing lowbush blueberry fruit ( Vaccinium angustifolium Ait.). Diss. Abstr. B 37(6) 2822: Order no. 76-28672.

Kalt, W., K.B. McRae, and L. C. Hamilton. 1995. Relationship between surface color and other maturity indicators in wild, lowbush blueberries. Can. J. Plant Sci. 75(2):485-490.

Kushman, L.J. and W.E. Ballinger. 1968. Acid and sugar changes during ripening in Wolcott blueberries. Proc. Amer. Soc. Hort. Sci. 92:290-295.
Markakis, P., A. Jarczyk, and S.P. Krishna. 1963. Nonvolatile acids of blueberries. J. Agr. Food Chem. 11(1):8-11.

Payne, R.W., P.W. Lane, P.G.N. Digby, S.A. Harding, P.K. Leech, G.W. Morgan, A.D. Todd, R. Thompson, G.T. Wilson, S.J. Welham, and R.P. White. 1993. Genstat 5 reference manual. release 2[2]. Clarendon Press, Oxford, U.K.

Riaz, M.N. and A.A. Bushway. 1994. Determinations of organic acids in raspberry cultivars grown in Maine. Fruit Var. J. 48(4):206-211.

Rubico, S.M. and M.R. McDaniel. 1992. Sensory evaluation of acids by free-choice profiling. Chem. Senses 17(3):273-289.

Ulrich, R. 1970. Organic acids, p.89-115. In: A.C. Hulme(ed.). The biochemistry of fruits and their products. Academic Press, London.

Wrolstad, R.E. 1976. Color and pigment analysis in fruit products. Oregon State Univ. Agr. Expt. Sta. Bul. 624. 